\title{
Prevalence of and risk factors for postoperative pulmonary complications after lung cancer surgery in patients with early-stage COPD
}

This article was published in the following Dove Press journal:

International Journal of COPD

16 June 2016

Number of times this article has been viewed

Eun Sun Kim'
Young Tae Kim²
Chang Hyun Kang'
In Kyu Park'
Won Bae'
Sun Mi Choi'
Jinwoo Lee'
Young Sik Park'
Chang-Hoon Lee'
Sang-Min Lee'
Jae-Joon Yim'
Young Whan Kim'
Sung Koo Han'
Chul-Gyu Yoo'
'Division of Pulmonary and Critical
Care Medicine, Department of
Internal Medicine, ${ }^{2 D e p a r t m e n t ~ o f ~}$
Thoracic and Cardiovascular Surgery,
Seoul National University College of
Medicine, Seoul, Republic of Korea

Correspondence: Chul-Gyu Yoo Division of Pulmonary and Critical Care Medicine, Department of Internal Medicine, Seoul National University College of Medicine, I0I, Daehak-ro, Jongno-gu, Seoul 03080, Republic of Korea

Tel +82 220723760

Fax +82 220720630

Email cgyoo@snu.ac.kr

\begin{abstract}
Purpose: This study aimed to investigate whether the prevalence of postoperative pulmonary complications (PPCs) in patients with non-small-cell lung cancer (NSCLC) is even higher in the early stages of COPD than in such patients with normal lung function and to verify the usefulness of symptom- or quality of life (QoL)-based scores in predicting risk for PPCs.

Patients and methods: Patients undergoing pulmonary resection for NSCLC between July 2012 and October 2014 were prospectively enrolled. Preoperative measurements of lung function, dyspnea, and QoL, operative characteristics, PPCs, duration of postoperative hospitalization, and in-hospital mortality were assessed.

Results: Among 351 consecutive patients with NSCLC, 343 patients with forced expiratory volume in 1 second $\left(\mathrm{FEV}_{1}\right) \geq 70 \%$ of predicted value were enrolled. At least one PPC occurred in 57 (16.6\%) patients. Prevalence of PPC was higher in patients with COPD (30.1\%) than in those with normal spirometry $(10.0 \% ; P<0.001)$. However, in patients with COPD, the prevalence of PPC was not different in patients with $\mathrm{FEV}_{1} \geq 70 \%$ compared to those with $\mathrm{FEV}_{1}<70 \%$ and between group A (low risk and less symptoms) and group B (low risk and more symptoms) patients with COPD, based on the new Global initiative for chronic Obstructive Lung Disease 2011 guidelines. In patients with COPD, body mass index (odds ratio [OR]: 0.80, $P=0.007$ ), carbon monoxide diffusing capacity of the lung $\left(\mathrm{DL}_{\mathrm{CO}}\right), \%$ predicted value $(\mathrm{OR}: 0.97, P=0.024)$, and operation time (OR: 1.01, $P=0.003$ ), but not COPD assessment test or St George Respiratory Questionnaire scores, were significantly associated with PPCs.

Conclusion: Even in patients with early-stage COPD, the prevalence of PPCs is higher than in patients with NSCLC with normal spirometry. However, this rate is not different between group A and group B patients with COPD. In accordance with this, scores based on symptoms or QoL are not predictors of risk of PPCs in patients with early-stage COPD.
\end{abstract}

Keywords: early COPD, postoperative pulmonary complication, prevalence, risk factor

\section{Introduction}

Lung cancer is a common fatal disease, and $<40 \%$ of all patients with lung cancer are candidates for a curative resection. Despite the improvement in surgical techniques and perioperative management, postoperative pulmonary complications (PPCs) still occur in $12 \%-40 \%$ of patients with lung cancer who have undergone surgical resection. ${ }^{1-6}$ $\mathrm{PPC}$ is one of the major causes of mortality following lung resection, accounting for up to $84 \%$ of all deaths. Other major significant clinical and economic impacts of PPCs include a prolonged hospital stay and the need for admission to the intensive care unit. ${ }^{7-9}$ Many previous studies ${ }^{8,10-22}$ have suggested that the patient's health status, age, sex, body mass index (BMI), history of smoking, chronic pulmonary disease, and 
preoperative pulmonary function tests (PFTs) are predictors of PPC. However, they have not been adopted widely in clinical practice, because none of them has been proven to be a sufficiently reliable predictor of PPCs, ${ }^{8,10-22}$ and further controlled trials are required before a consensus regarding these predictors can be established.

In recent years, lung cancer in never-smokers with normal lung function has increasingly been detected, owing to the routine health examination now widely performed in Korea and other countries. ${ }^{23,24}$ In patients who have been surgically resected, well-known risk factors, such as poor PFT or smoking status, have not been useful for predicting PPCs. It is unclear whether the prevalence of and risk factors for PPCs in patients with lung cancer are different between patients with early-stage COPD and those with a normal PFT. In addition, the difference in the prevalence between group A (low risk and less symptoms) and group B (low risk and more symptoms) patients with COPD, based on the new Global initiative for chronic Obstructive Lung Disease (GOLD) 2011 guidelines, has not been studied yet.

To address these problems, we have prospectively enrolled patients with non-small-cell lung cancer (NSCLC) undergoing curative surgery and we have compared the prevalence of and risk factors for PPCs between patients with COPD with forced expiratory volume in 1 second $\left(\mathrm{FEV}_{1}\right) \geq 70 \%$ and patients with a normal PFT. In addition, we also evaluated whether dyspnea or quality of life (QoL)based scores, such as the COPD assessment test (CAT) or St George Respiratory Questionnaire (SGRQ) scores, play a role in the prediction of PPCs.

\section{Patients and methods \\ Study design and patients}

All patients undergoing thoracic surgery for lung cancer were prospectively enrolled between July 2012 and October 2014 in the Department of Thoracic and Cardiovascular Surgery at the Seoul National University Hospital (SNUH). The following patients were excluded: those without available PFT results prior to surgery, those with an $\mathrm{FEV}_{1}$ value $<70 \%$ of the predicted value, those with histological diagnosis of small cell carcinoma, those with incomplete data, and those who had not given informed consent. Emergency procedures were also excluded from the analysis.

All surgical procedures were performed under general anesthesia with single lung ventilation. Patients underwent lung resection for NSCLC by either an open approach or a thoracoscopic approach. The surgical approach was decided by experienced thoracic surgeons. Postoperative pain control was achieved by continuous thoracic epidural anesthesia or systemic opioids (parenteral administration or intravenous patient-controlled administration). All patients received daily physiotherapy from the first postoperative day, comprising deep breathing exercises, incentive spirometry, supported coughing, and mobilization. The study was approved by the Institutional Review Board and Ethics Committee of SNUH (IRB number H-1308-084-514) and was conducted in compliance with the Declaration of Helsinki. Written informed consent was obtained from all patients.

\section{Preoperative evaluation}

Preoperative evaluation for all patients included obtaining demographic information and detailed medical history, a physical examination, blood and urine examinations, a 12-lead electrocardiogram, and a chest radiograph (CXR). The five grades of the American Society Anesthesiology classification were used as a composite index of each patient's overall health status. All participating patients completed the following questionnaires: the Modified Medical Research Council (mMRC) scale, the CAT, and the SGRQ. Preoperative PFTs with bronchodilator responses were conducted in all patients.

\section{Definitions}

COPD diagnoses were confirmed by spirometry, defined by a postbronchodilator $\mathrm{FEV}_{1}$ / functional vital capacity (FVC) ratio of $<70 \%$, and early stage of COPD was defined as $\mathrm{FEV}_{1} \geq 70 \%$ of the predicted value. ${ }^{25}$

Patients with COPD were classified into the following four groups based on symptoms, airflow obstruction, and exacerbation history: ${ }^{26}$ group A, low risk and low symptom burden; group B, low risk and higher symptom burden; group $\mathrm{C}$, high risk and low symptom burden; group D, high risk and higher symptom burden. High risk was defined as $\mathrm{FEV}_{1}<50 \%$ predicted value and high exacerbation risk ( $\geq 2 /$ year), and a higher symptom burden was defined by mMRC $\geq 2$ or CAT $\geq 10$. Posttuberculosis (TB) lesions on CXR were defined as follows: a previous history of anti-TB treatments, a negative acid-fast bacilli smear and mycobacterial culture for TB on the sputum sample, and the presence of scarring, fibrosis, cavitation, emphysema, or other destructive lung changes on CXR.

PPCs were defined as follows: ${ }^{10}$ atelectasis requiring bronchoscopy; bacterial pneumonia (confirmed by infiltrative shadows on CXR, positive sputum culture, body temperature $\geq 37.5^{\circ} \mathrm{C}$, and white blood cell count $>10,000 / \mu \mathrm{L}$ ); empyema (positive bacterial infection with pleural effusion); acute interstitial pneumonia (aggravation of dyspnea upon exertion, deterioration of arterial blood gases, and diffuse interstitial abnormalities compatible with acute interstitial pneumonia); 
mechanical ventilation $\geq 3$ days; reintubation within 48 hours; tracheostomy; bronchial stump dehiscence; and persistent air leak (air leak for $>5$ days or patients undergoing an intervention for a large-volume air leak prior to Day 6).

\section{Data collection}

All patients were followed up after surgery and all complications occurring prior to discharge were recorded. Data collected included demographic characteristics, operative procedure and time, pathologic diagnosis, hospital length of stay (LOS), in-hospital mortality, and PPCs.

\section{Statistical analysis}

On the basis of the results of previous studies, ${ }^{1-6,27}$ we assumed that the average rate of PPCs would be $31 \%$ in the patients with COPD and $14 \%$ in those without COPD. A study design with a 1:2 allocation of COPD group: non-COPD group, with a significance level of 0.05 and using a two-sided, two-sample $t$-test, with a power of $90 \%$, would require 100 patients in the COPD group and 200 patients in the non-COPD group. Allowing for a $15 \%$ dropout rate over the study period, the total sample size required for the study is 345 individuals.

Unless otherwise specified, results are expressed as mean (standard deviation) or median (range) for continuous variables and as a percentage for categorical variables. Student's $t$-test was used to compare continuous variables, and the chi-square or Fisher's exact tests were used to compare categorical variables. The variables with $P<0.01$ in univariate analysis were entered into a multivariate logistic regression analysis to identify independent predictors of PPCs. The model selection for the regression analyses was based on a stepwise procedure, which alternates between dropping the least significant variable from the model and then reconsidering all potential variables for reintroduction into the model until no further variables can be added. Group analysis was also performed to investigate different risk factors according to COPD status. Unless otherwise noted, all tests were two-sided and were performed at the 0.05 significance level. Analyses were performed using SPSS 20.0 (IBM Corporation, Armonk, NY, USA).

\section{Results \\ Preoperative patient characteristics}

Three hundred and seventy-three patients diagnosed with NSCLC between July 2012 and October 2014 at Seoul National University Hospital, a university-affiliated tertiary care hospital in Korea, were eligible for curative resection. Thirty patients were excluded from the study due to unexpected inoperable stage, eg, only an "open and closure" operation could be performed, because of pleural nodules found during surgery $(n=16)$; incomplete data available in questionnaires $(n=4)$; no available preoperative PFT $(n=1)$; refusal of operation $(\mathrm{n}=1)$; and $\mathrm{FEV}_{1}<70 \%$ predicted value $(n=8)$ (Figure 1). Baseline characteristics of the 343 patients

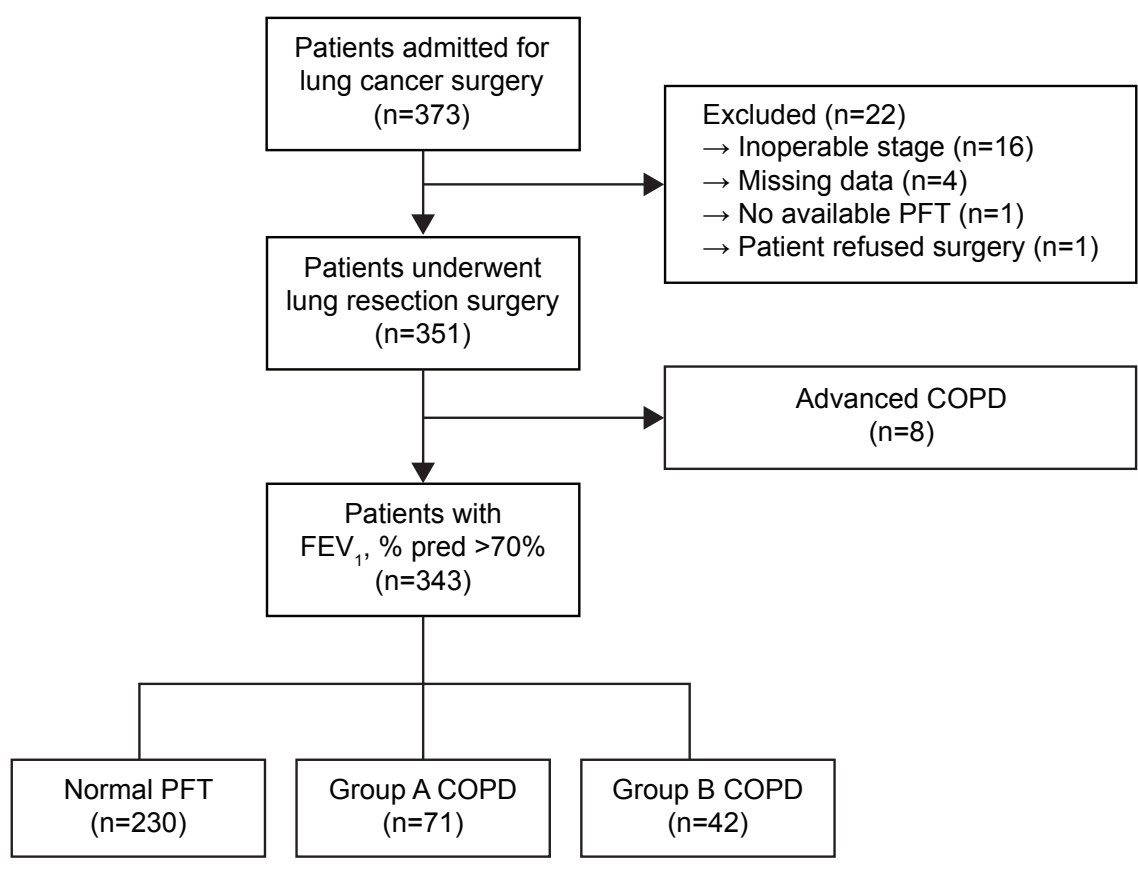

Figure I Flow diagram for patient recruitment.

Note: Group A, low risk and less symptoms; group B, low risk and more symptoms.

Abbreviations: $\mathrm{FEV}_{1}$, forced expiratory volume in I second; \% pred, percentage of the predicted value; PFT, pulmonary function test. 
are shown in Table 1. Of the 343 patients, $236(68.8 \%)$ patients were male, and the median age of the cohort was 66.2 (27-84) years. The mean BMI was 23.1 (standard deviation: 3.0) $\mathrm{kg} / \mathrm{m}^{2}$. The American Society Anesthesiology score of most $(95.0 \%)$ of the patients was one or two. Among 343 patients, 113 (32.9\%) patients had COPD with $\mathrm{FEV}_{1} \geq 70 \%$. The median duration of COPD from the diagnosis was 3.4 (1-24) months, and no patients used oral or inhaled steroids. Five patients had a short-acting beta-2-agonist inhaler on an as-needed basis. Only one patient experienced acute exacerbation of COPD $\sim 18$ months ago. They were older $(P<0.001)$ and had a higher proportion of ever-smokers $(P<0.001)$. However, preoperative comorbidities, including diabetes, hypertension, chronic liver disease, and chronic kidney disease, were not significantly different between patients with and those without early-stage COPD. Table 2 shows the results of preoperative evaluation of lung function, dyspnea, and QoL. The percent predicted values for $\mathrm{FEV}_{1}, \mathrm{FVC}, \mathrm{FEV}_{1}$ / FVC, and carbon monoxide diffusing capacity of the lung $\left(\mathrm{DL}_{\mathrm{CO}}\right)$ were significantly lower in the COPD group than in the non-COPD group $(P<0.05)$. Both mMRC and CAT scores were not significantly different between patients with and those without early-stage COPD, but patients with earlystage COPD had a higher SGRQ symptom score $(P<0.001)$. A higher trend in activity scores and total scores of SGRQ was observed in the COPD group than in the non-COPD group, but the differences were not statistically significant.

\section{Operative characteristics}

Two hundred and thirty-four (68.2\%) patients underwent a video-assisted thoracic surgery and 109 (31.8\%) underwent thoracotomy. The proportion of patients who underwent thoracotomy was significantly higher in the COPD group than in the non-COPD group $(P=0.001)$. The extent of lung resections was as follows: wedge resections or segmentectomies $(6.7 \%)$, lobectomies or bilobectomies $(88.0 \%)$, and pneumonectomies (5.3\%). These were not different between the COPD and non-COPD groups. The median operative time was 170.7 (53-410) minutes, and patients with COPD had significantly longer operative times $(P<0.001)$. Adenocarcinoma was the most common histological type of cancer $(62.4 \%)$, followed by squamous cell carcinoma (32.4\%). As expected, adenocarcinoma was the most frequent histological type in the non-COPD group, while squamous cell carcinoma was more frequent than adenocarcinoma in the COPD group. The pathological stage in more than half of the patients was stage I, and this was not different between the COPD and non-COPD groups (all patients: stage I: 56.3\%; stage II: $19.5 \%$; stage III: $22.7 \%$; stage IV: $1.5 \%$ ).

\section{COPD grades and groups}

Among the 113 patients with early-stage COPD, 87 (77.0\%) patients had a mild grade and the other $26(23.0 \%)$ patients had a moderate grade of COPD. The patient distribution according to the newly defined COPD groups revealed that

Table I Demographic characteristics of study patients

\begin{tabular}{|c|c|c|c|c|c|c|c|}
\hline & \multirow{2}{*}{$\begin{array}{l}\text { Total } \\
(n=343)\end{array}$} & \multirow{2}{*}{$\begin{array}{l}\text { Normal PFT } \\
(n=230)\end{array}$} & \multicolumn{4}{|l|}{ Early COPD } & \multirow[t]{2}{*}{$P$-value } \\
\hline & & & Total $(n=|| 3)$ & Group A $(n=7 I)$ & Group B $(n=42)$ & $P$-value & \\
\hline Sex, male & $236(68.8)$ & $|3|(57.0)$ & 105 (92.9) & $67(94.4)$ & $38(90.5)$ & 0.436 & $<0.001$ \\
\hline Age, years & $66.2(27-84)$ & $64(27-84)$ & $70.5(5 I-84)$ & 70.1 (53-84) & $7 I .3(5 I-8 I)$ & 0.639 & $<0.001$ \\
\hline $\mathrm{BMI}, \mathrm{kg} / \mathrm{m}^{2}$ & $23.1(3.0)$ & $23.2(3.0)$ & $23.0(3.1)$ & $23.1(2.8)$ & $22.5(3.6)$ & 0.315 & 0.445 \\
\hline \multicolumn{8}{|l|}{ Smoking status } \\
\hline Never & $128(37.3)$ & 117 (50.9) & II (9.7) & $6(8.5)$ & $5(11.9)$ & 0.475 & $<0.001$ \\
\hline Ex-smoker & $117(34.1)$ & $63(27.4)$ & $54(47.8)$ & $37(52.1)$ & $17(40.5)$ & & \\
\hline Current-smoker & $98(28.6)$ & $50(21.7)$ & $48(42.5)$ & $28(39.4)$ & $20(47.6)$ & & \\
\hline Smoking pack-year & $20.1(0-224)$ & $2.4(0-120)$ & $39.8(0-224)$ & $39.1(0-224)$ & $42.0(0-110)$ & 0.532 & $<0.001$ \\
\hline Diabetes mellitus & $68(19.8)$ & $44(19.1)$ & $24(21.2)$ & $19(26.8)$ & $5(11.9)$ & 0.062 & 0.645 \\
\hline Hypertension & $128(37.3)$ & $81(35.2)$ & 47 (4I.6) & $31(43.7)$ & $16(38.1)$ & 0.562 & 0.251 \\
\hline Chronic liver disease & $9(2.6)$ & $6(2.6)$ & $3(2.7)$ & $3(4.2)$ & $0(0.0)$ & 0.293 & 0.980 \\
\hline Chronic kidney disease & $7(2.0)$ & $3(1.3)$ & $4(3.5)$ & $2(2.8)$ & $2(4.8)$ & 0.627 & 0.224 \\
\hline Post-TB lesions on CXR & 40 (II.7) & $21(8.7)$ & $19(16.8)$ & II (I5.5) & $8(19.0)$ & 0.625 & 0.037 \\
\hline \multicolumn{8}{|l|}{ ASA class, n (\%) } \\
\hline $\mathrm{I}, 2$ & $326(95.0)$ & $222(96.5)$ & $104(92.0)$ & $65(91.5)$ & $39(92.9)$ & 0.864 & 0.072 \\
\hline 3,4 & $17(5.0)$ & $8(3.5)$ & $9(8.0)$ & $6(8.5)$ & $3(7.1)$ & & \\
\hline Previous solid cancer $\mathrm{Hx}$ & $50(14.6)$ & $35(15.2)$ & $15(13.3)$ & $12(16.9)$ & $3(7.1)$ & 0.140 & 0.632 \\
\hline Neoadjuvant CTx & $6(1.7)$ & $5(2.2)$ & $\mathrm{I}(0.9)$ & I (I.4) & $0(0.0)$ & 1.000 & 0.668 \\
\hline
\end{tabular}

Notes: Significant differences between patients with and without COPD were tested using chi-square or Fisher's exact test. Data are represented as mean (SD), number (\%) patients, or median (range). Group A, low risk and less symptoms; group B, low risk and more symptoms.

Abbreviations: ASA, American Society Anesthesiology; BMI, body mass index; CTx, chemotherapy; CXR, chest radiograph; Hx, history; PFT, pulmonary function test; SD, standard deviation; TB, tuberculosis. 
Table 2 Preoperative evaluation: PFT, mMRC, CAT, and SGRQ questionnaire

\begin{tabular}{|c|c|c|c|c|c|c|c|}
\hline & \multirow{2}{*}{$\begin{array}{l}\text { Total } \\
(n=343)\end{array}$} & \multirow{2}{*}{$\begin{array}{l}\text { Normal PFT } \\
(n=230)\end{array}$} & \multicolumn{4}{|l|}{ Early COPD } & \multirow[t]{2}{*}{$P$-value } \\
\hline & & & Total $(n=|| 3)$ & Group A $(n=7 I)$ & Group B $(n=42)$ & $P$-value & \\
\hline \multicolumn{8}{|l|}{ PFT } \\
\hline $\mathrm{FEV}_{1}, \%$ pred & $102.8(17.8)$ & $107.9(17.1)$ & $92.4(14.4)$ & $92.8(13.5)$ & 91.8 (I5.9) & 0.725 & $<0.001$ \\
\hline FVC, \% pred & $100.1(15.0)$ & $98.3(15.0)$ & $103.7(14.2)$ & $102.8(12.8)$ & $105.2(16.4)$ & 0.387 & 0.002 \\
\hline $\mathrm{FEV}_{1} / \mathrm{FVC}(\%)$ & $72.3(10.4)$ & $77.9(6.8)$ & $60.9(6.3)$ & $61.7(6.0)$ & $59.7(6.6)$ & 0.106 & $<0.001$ \\
\hline $\mathrm{DL}_{\mathrm{co}}, \%$ pred & $94.2(19.8)$ & $95.8(20.2)$ & $91.0(18.8)$ & $92.6(19.4)$ & $88.2(17.7)$ & 0.229 & 0.034 \\
\hline mMRC scale $\geq 2$ & $4 I(12.0)$ & $23(10.0)$ & $18(15.9)$ & $0(0.0)$ & $18(42.9)$ & $<0.001$ & 0.115 \\
\hline CAT score $\geq 10$ & 95 (27.7) & $59(25.7)$ & $36(31.9)$ & $0(0.0)$ & $36(85.7)$ & $<0.001$ & 0.246 \\
\hline \multicolumn{8}{|l|}{ SGRQ score } \\
\hline Symptom & $19.0(0.0-87.0)$ & $16.5(0.0-82.2)$ & $23.5(0.0-87.0)$ & $18.4(0.0-67.9)$ & $25.8(9.7-87.0)$ & $<0.001$ & $<0.001$ \\
\hline Activity & $23.3(0.0-100.0)$ & $21.8(0.0-79.7)$ & $23.4(0.0-100.0)$ & $17.8(0.0-53.2)$ & $42.4(11.2-100.0)$ & $<0.001$ & 0.059 \\
\hline Impacts & $4.6(0.0-89.9)$ & $4.6(0.0-55.5)$ & $4.5(0.0-89.9)$ & $3.3(0.0-23.8)$ & $10.7(0.0-89.9)$ & $<0.001$ & 0.552 \\
\hline Total & | 3.1 (0.0-84.7) & $12.5(0.0-54.7)$ & I 4.7 (0.8-84.7) & $10.5(0.8-28.5)$ & $25.4(6.9-84.7)$ & $<0.001$ & 0.071 \\
\hline SGRQ total score $\geq 25$ & $75(21.9)$ & $54(23.5)$ & $25(22.1)$ & $2(2.8)$ & $22(52.4)$ & $<0.001$ & 0.968 \\
\hline \multicolumn{8}{|c|}{ Pathology staging (carcinoid, carcinosarcoma, neuroendocrine carcinoma) } \\
\hline $\mathrm{IA} / \mathrm{B}$ & $193(56.3)$ & $128(55.6)$ & $65(57.5)$ & $42(59.2)$ & $23(54.7)$ & 0.110 & 0.136 \\
\hline$\| \mathrm{I} / \mathrm{IIB}$ & $67(19.5)$ & $40(17.5)$ & $27(23.9)$ & I5 (2I.I) & $12(28.6)$ & & \\
\hline IIIA/IIIB & $78(22.7)$ & $57(24.7)$ & $21(18.6)$ & $14(19.7)$ & $7(16.7)$ & & \\
\hline IV & $5(1.5)$ & $5(2.2)$ & $0(0.0)$ & $0(0.0)$ & $0(0.0)$ & & \\
\hline
\end{tabular}

Notes: Significant differences between patients with and without COPD were tested using chi-square or Fisher's exact test. Data are represented as mean (SD), number (\%) patients, or median (range). Group A, low risk and less symptoms; group B, low risk and more symptoms.

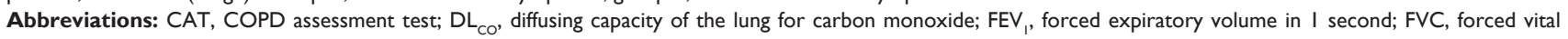
capacity; mMRC, modified Medical Research Council; \% pred, percentage of the predicted value; PFT, pulmonary function test; SD, standard deviation; SGRQ, St George Respiratory Questionnaire.

$71(62.8 \%)$ patients belonged to group A and $42(37.2 \%)$ patients to group B. None of the patients in this study belonged to group $\mathrm{C}$ or $\mathrm{D}$. The demographic, preoperative, and operative characteristics were similar in patients with mild and those with moderate COPD grades, except for the PFT values $\left(\mathrm{FEV}_{1}, \%\right.$ pred, FVC, \% pred, $\mathrm{FEV}_{1} / \mathrm{FVC}(\%)$, all $P<0.001)$ and the proportion of patients with mMRC scale $\geq 2(P=0.018)$. In the COPD groups, differences were noted only in questionnaires, such as the mMRC scale, CAT score, and SGRQ score (all $P<0.001$; Table 2).

\section{Postoperative outcomes}

The postoperative outcomes are demonstrated in Table 3. PPCs occurred in 57 (16.6\%) patients. Persistent air leak was the most frequent PPC, followed by bacterial pneumonia and atelectasis requiring bronchial toileting by bronchoscopy. PPCs were more commonly seen in patients with early-stage COPD (34 patients, 30.1\%) than in those without COPD (23 patients, $10.0 \% ; P<0.001$ ). In contrast, the prevalence of PPCs was not different between patients with $\mathrm{FEV}_{1} \geq 70 \%$ and those with $\mathrm{FEV}_{1}<70 \%$ or between group A patients and

Table 3 Postoperative outcomes

\begin{tabular}{|c|c|c|c|c|c|c|c|}
\hline & \multirow{2}{*}{$\begin{array}{l}\text { Total } \\
(n=343)\end{array}$} & \multirow{2}{*}{$\begin{array}{l}\text { Normal PFT } \\
(n=230)\end{array}$} & \multicolumn{4}{|l|}{ Early COPD } & \multirow[t]{2}{*}{$P$-value } \\
\hline & & & Total $(n=|| 3)$ & Group A $(n=7 I)$ & Group B $(n=42)$ & $P$-value & \\
\hline PPCs & $57(16.6)$ & $23(10.0)$ & $34(30.1)$ & $17(23.9)$ & $17(40.5)$ & 0.064 & $<0.001$ \\
\hline Persistent air leak & $30(8.7)$ & $15(6.5)$ & $15(13.3)$ & $9(12.7)$ & $6(14.3)$ & 0.807 & 0.037 \\
\hline Bacterial pneumonia & $28(8.2)$ & II (4.8) & $17(15.0)$ & $7(9.9)$ & $10(23.8)$ & 0.045 & 0.001 \\
\hline Atelectasis requiring BFS & $8(2.3)$ & $4(1.7)$ & $4(3.5)$ & $3(4.2)$ & I (2.4) & 1.000 & 0.299 \\
\hline Reintubation within 48 hours & $5(1.5)$ & $5(2.2)$ & $0(0.0)$ & $0(0.0)$ & $0(0.0)$ & - & 0.176 \\
\hline Prolonged MV & $4(1.2)$ & $4(1.7)$ & $0(0.0)$ & $0(0.0)$ & $0(0.0)$ & - & 0.306 \\
\hline Tracheostomy & $3(0.9)$ & $3(1.3)$ & $0(0.0)$ & $0(0.0)$ & $0(0.0)$ & - & 0.554 \\
\hline AIP & $\mathrm{I}(0.3)$ & I (0.4) & $0(0.0)$ & $0(0.0)$ & $0(0.0)$ & - & 1.000 \\
\hline Empyema & I $(0.3)$ & $0(0.0)$ & I (0.9) & $0(0.0)$ & I (2.4) & 0.372 & 0.329 \\
\hline Hospital LOS, days & $7.8(3-157)$ & $7.3(3-157)$ & $8.7(4-37)$ & $8.6(4-34)$ & $9.0(5-37)$ & 0.114 & 0.265 \\
\hline In-hospital death & $3(0.9)$ & $3(1.3)$ & $0(0.0)$ & $0(0.0)$ & $0(0.0)$ & - & 0.554 \\
\hline
\end{tabular}

Notes: Significant differences between patients with and without COPD were tested using chi-square or Fisher's exact test. Data are represented as mean (SD), number (\%) patients, or median (range). Group A, low risk and less symptoms; group B, low risk and more symptoms.

Abbreviations: AIP, acute interstitial pneumonia; BFS, bronchoscopy; LOS, length of stay; MV, mechanical ventilation; PFT, pulmonary function test; PPCs, postoperative pulmonary complications; SD, standard deviation. 
group B patients. Among the 34 patients with COPD with PPCs, six (17.6\%) patients had moderate COPD grades and $17(50.0 \%)$ patients were included in COPD group B. The degree of airflow limitation in patients with COPD was not significantly associated with PPCs $(P=0.374)$, but the COPD group tended to have more PPCs, although this did not reach statistical significance $(P=0.064)$. Although PPCs were prevalent in patients with early-stage COPD than in those with a normal PFT, hospital LOS, and in-hospital mortality were not significantly different between these groups. In contrast, LOS was significantly longer in patients with PPCs (median: 14.1 days) than in patients without PPCs (median: 7.3 days; $P<0.001$ ).

\section{Risk factors for PPCs}

We evaluated the variables that were significantly associated with PPCs in univariate analyses $(P<0.05)$. Although some of these variables are clinically related to each other (eg, smoking, COPD, and post-TB lesions on CXR), none were sufficiently collinear by Spearman correlation coefficients to exclude as candidates for multivariable analysis. Multivariate logistic regression analysis was used to identify preoperative variables independently associated with PPCs (Table 4). Eligible variables were limited to those significantly associated with PPCs at $P \leq 0.01$. The perioperative variables significantly independently associated with PPCs included the following: COPD (odds ratio [OR]: 3.42; 95\% CI: $1.775-6.596 ; P<0.001$ ); post-TB lesion on CXR (OR: 2.73; 95\% CI: $1.178-6.345 ; P=0.019)$; BMI (OR: $0.77 ; 95 \%$ CI: $0.688-0.870 ; P<0.001), \mathrm{DL}_{\mathrm{CO}}, \%$ pred (OR: 0.97; 95\% CI: $0.957-0.991 ; P=0.003$ ), and operative time (OR: 1.01; 95\% CI: $1.001-1.012 ; P=0.004)$.

Table 4 Multivariate analysis of risk factors for PPCs

\begin{tabular}{|c|c|c|c|}
\hline Variable & OR & $95 \% \mathrm{Cl}$ & $P$-value \\
\hline \multicolumn{4}{|l|}{ All patients } \\
\hline COPD & 3.42 & $1.775-6.596$ & $<0.001$ \\
\hline Post-TB lesion on CXR & 2.73 & $1.178-6.345$ & 0.019 \\
\hline $\mathrm{BMI}, \mathrm{kg} / \mathrm{m}^{2}$ & 0.77 & $0.688-0.870$ & $<0.001$ \\
\hline $\mathrm{DL}_{\mathrm{co}}, \%$ pred & 0.97 & $0.957-0.991$ & 0.003 \\
\hline Operation time (minutes) & 1.01 & $1.002-1.012$ & 0.004 \\
\hline \multicolumn{4}{|l|}{ Patients with early COPD } \\
\hline BMI, kg/m² & 0.80 & $0.68 I-0.94 I$ & 0.007 \\
\hline $\mathrm{DL}_{\mathrm{co}}, \%$ pred & 0.97 & $0.944-0.996$ & 0.024 \\
\hline Operation time (minutes) & 1.01 & $1.004-1.018$ & 0.003 \\
\hline \multicolumn{4}{|l|}{ Non-COPD patients } \\
\hline Post-TB lesion on CXR & 4.43 & $1.248-15.690$ & 0.021 \\
\hline Sex, male & 3.39 & $1.059-10.858$ & 0.040 \\
\hline $\mathrm{BMI}, \mathrm{kg} / \mathrm{m}^{2}$ & 0.71 & $0.589-0.85 \mathrm{I}$ & $<0.001$ \\
\hline $\mathrm{DL}_{\mathrm{co}}, \%$ pred & 0.97 & $0.943-0.990$ & 0.005 \\
\hline
\end{tabular}

Abbreviations: $\mathrm{BMI}$, body mass index; $\mathrm{CXR}$, chest radiograph; $\mathrm{DL}_{\mathrm{co}}$, diffusing capacity of the lung for carbon monoxide; OR, odds ratio; \% pred, percentage of the predicted value; PPCs, postoperative pulmonary complications; TB, tuberculosis.
Then, we evaluated risk factors for PPCs in patients with or without COPD, separately. In the COPD group, $\mathrm{BMI}(P=0.016)$, COPD subgroup $(P=0.064), \mathrm{DL}_{\mathrm{CO}}, \%$ pred $(P=0.064)$, CAT score $(P=0.059)$, SGRQ total score $\geq 25(P=0.086)$, and operation times $(P=0.002)$ were associated with PPCs in univariate analyses (Table S1). Upon multivariate analysis, BMI (OR: 0.80; 95\% CI: $0.681-0.941 ; P=0.007), \mathrm{DL}_{\mathrm{CO}}, \%$ pred (OR: 0.97; 95\% CI: $0.944-0.996 ; P=0.024)$, and operation time (OR: $1.01 ; 95 \%$ CI: $1.004-1.018 ; P=0.003$ ), but not COPD group, remained significant predictors of PPCs for patients with COPD (Table 4). In patients without COPD, male sex $(P=0.030)$, BMI $(P<0.001)$, post-TB lesion on CXR ( $P=0.003)$, SGRQ symptom $(P=0.004)$, activity $(P=0.034)$, impact $(P=0.053)$, total score $(P=0.010)$, and SGRQ total score $\geq 25(P=0.008)$ were associated with higher PPC rates in univariate analysis (Table S1). On multivariate analysis, post-TB lesion (OR: 4.43 ; 95\% CI: 1.248-15.690; $P=0.021$ ), male sex (OR: $3.39 ; 95 \%$ CI: $1.059-10.858 ; P=0.040$ ), BMI (OR: $0.71 ; 95 \%$ CI: $0.589-0.851 ; P<0.001$ ), and $\mathrm{DL}_{\mathrm{CO}}$, \% pred (OR: 0.97; 95\% CI: 0.943-0.990; $P=0.005$ ) were independent predictors of PPCs after lung resection in patients without COPD (Table 4).

\section{Discussion}

These days, routine health examinations are undertaken widely, and this has resulted in identification of increased proportions of patients with lung cancer with relatively preserved lung function. In this study, 343 patients undergoing thoracic surgery for lung cancer were prospectively enrolled over a period of 28 months. Most of them had normal or slightly compromised lung function, and only 26 (7.6\%) patients had a moderate degree of airflow obstruction. The eight patients with $\mathrm{FEV}_{1}<70 \%$ of predicted value who were excluded also had a moderate degree of airflow limitation; no patients with severe or very severe airflow obstruction underwent thoracic surgery during the study period. This trend was parallel to our aim to find new risk factors for PPCs in patients with relatively preserved lung function.

Previously published studies ${ }^{8,28-31}$ have shown COPD to be a well-known risk factor for PPCs, probably because of impairment of gas exchange and mucociliary clearance of aspirated bacteria. However, no prior studies have been conducted in patients with relatively preserved lung function. Therefore, we evaluated whether the prevalence of and risk factors for PPCs were different between patients with early COPD with $\mathrm{FEV}_{1} \geq 70 \%$ and those with a normal PFT. Compared to patients without COPD, patients with early COPD with $\mathrm{FEV}_{1} \geq 70 \%$ had a higher rate of PPCs (30.1\% vs $10.0 \%, P<0.001)$. The prevalence of PPCs according to 
the GOLD criteria for classification of COPD has not been evaluated. Among patients with early COPD, PPCs were more commonly seen in patients belonging to group $\mathrm{B}$ than in those belonging to group A $(40.5 \%$ vs $23.9 \%, P=0.064)$. Bacterial pneumonia occurred more frequently in group $B$ than in group A patients $(23.8 \%$ vs $9.9 \%, P=0.045)$. However, neither COPD grades nor the degrees of airflow obstruction were significantly associated with PPCs $(P=0.374)$. Therefore, we evaluated the utility of symptom-based scoring systems, such as mMRC, CAT, or SGRQ, in the prediction of PPCs. The proportion of patients with CAT score $\geq 10$ or SGRQ total score $\geq 25$ was higher in patients with PPCs ( $P=0.059$ and $P=0.086$, respectively), and COPD group $B$ patients had a higher PPC rate than group A patients $(P=0.064)$, which indicates the importance of the preoperative symptom burden. However, these were not significant in multiple regression analyses. There are several potential explanations for this finding. Our study population included a high proportion of patients with asymptomatic lung cancer. They were diagnosed because of a solitary pulmonary nodule on routine CXR screening, and COPD was diagnosed in the process of the lung cancer workup. Furthermore, these patients were typically functionally independent and had fewer comorbidities.

Our study demonstrated four independent perioperative risk factors for PPCs after lung resection surgery, other than COPD: old TB lesions on $\mathrm{CXR}$, low $\mathrm{DL}_{\mathrm{CO}}$, low $\mathrm{BMI}$, and longer operation times. Low $\mathrm{BMI}$ and $\mathrm{DL}_{\mathrm{CO}}$ were common risk factors for PPCs in both the COPD group and the nonCOPD group. In this study, preoperative values and predicted values of $\mathrm{FEV}_{1}, \mathrm{FEV}_{1} / \mathrm{FVC}$, and $\mathrm{DL}_{\mathrm{CO}}$ were all significantly lower in the PPC group $(P<0.05)$. However, once COPD is taken into account, those PFT values were no longer independent factors for predicting PPCs, except $\mathrm{DL}_{\mathrm{CO}}$. Patients with preoperative $\mathrm{FEV}_{1}$ and $\mathrm{DL}_{\mathrm{CO}}<60 \%$ predicted value have been shown to have increased risk of postoperative complications in previous studies. ${ }^{32,33}$ This study revealed that $\mathrm{DL}_{\mathrm{CO}}$ was the most useful spirometric parameter for assessing the risk of PPCs even in patients with $\mathrm{FEV}_{1}$ and $\mathrm{DL}_{\mathrm{CO}}$ $>70 \%$. A lower BMI was also significantly associated with higher rates of PPCs in both groups of patients. A number of studies have shown that a low BMI is associated with a poor prognosis in patients with COPD. ${ }^{34-37}$ However, this study revealed that low BMI was an independent risk factor for PPCs even in patients without COPD. Lower BMI is often associated with protein depletion, which in turn is associated with impairment of respiratory muscle strength, reduction in diaphragmatic muscular mass, and maximum voluntary ventilation, predisposing the patient to more PPCs. ${ }^{38,39}$
Longer operation time was a specific risk factor for patients with COPD, whereas post-TB lesions on CXR and male sex were important factors that increased the risk of PPCs in patients without COPD. Licker et $\mathrm{al}^{40}$ showed that prolonged surgery was independently associated with an increased risk of postoperative complications. Surgery time can be influenced by the patient's status, the complexity of the surgery, and the surgeon's skill level. In addition, patients with severe adhesions would require longer operating time. ${ }^{41}$ We also found that the duration of surgery was another independent significant risk factor for complications, particularly in patients with COPD. Therefore, we suggest that lung resection for patients with COPD should be performed by an experienced surgical team and that the surgery duration should be limited to the shortest possible time. Post-TB lesions on CXR were found to be an important risk factor for PPCs in patients without COPD. We attempted to restrict smoking status when defining post-TB lesions, because a smoking history could potentially have biased the estimated effect of TB on loss of lung function and on PPCs. Even after adjustment for both smoking status and pack-years, post-TB lesions were still significantly associated with increased risk of PPCs ( $P=0.002)$. This is the first prospective study to show that post-TB lesions on CXR is an independent risk factor for PPCs. Previously, Lawrence et $\mathrm{al}^{12}$ found that abnormal CXR was associated with a three-fold increase in PPCs compared with the occurrence in the absence of this finding. However, abnormal CXR could be nonspecific, because it is affected by various cardiopulmonary diseases. ${ }^{12}$ Recently, a cohort study, based on a nationwide representative sampling of Korean subjects, reported that previous TB lesions on CXR comprise a risk factor for obstructive lung disease and even a minimal TB lesion was also a strong risk factor in neversmokers. ${ }^{42}$ Our findings supported those of previous reports. In this study, patients with post-TB lesions showed a higher percentage of COPD than patients without such findings $(P<0.040)$. This result can be explained by considering the destructive and fibrosing properties of pulmonary TB, causing pulmonary overdistension. ${ }^{43}$ Male sex was another important risk factor for PPCs in patients without COPD. There were 131 (57\%) male patients in the non-COPD group, which was significantly lower than the number in the COPD group. After adjustment for both smoking status and pack-years, male sex was still significantly associated with an increased rate of PPCs $(P=0.030)$. Some recent studies showed that male patients have a higher risk of complications in open and laparoscopic colorectal surgery, ${ }^{44}$ but no study has suggested that male sex is a specific risk factor for PPCs after thoracic surgery, especially in patients with normal lung function. 
Genetic differences or compliance with a daily physiotherapy from the first postoperative day comprising deep breathing exercise, incentive spirometry, supported coughing, and mobilization might be plausible explanations for this, but further study is needed to confirm these findings.

There are several limitations to this study. First, this study was conducted in only one tertiary referral hospital, and the results may have limited generalizability to other populations. A prospective multicenter study with an appropriate spectrum of patients with COPD and normal patients would be necessary to validate predictors identified in our study and to define the best predictors of PPCs more rigorously. However, serious PPCs, even in patients with severe COPD, are infrequent. ${ }^{45}$ This low event rate, combined with the small number of patients with severe COPD undergoing lung resection surgery, would necessitate a large sample size for any prospective study. Second, we followed up our patients during their hospitalization, and thus we evaluated only the short-term impact of the various factors on PPCs. Longitudinal studies are needed to evaluate the long-term clinical impact of PPCs, such as the number of readmissions and all-cause mortality after PPCs.

\section{Conclusion}

In patients with NSCLC, the prevalence of PPCs is higher even in early stages of COPD than in such patients with normal spirometry. Symptom- or QoL-based scores, such as CAT or SGRQ scores, are not significant risk predictors for PPCs in patients with early-stage COPD.

\section{Acknowledgments}

The authors acknowledge the patients with NSCLC who allowed us to conduct clinical research studies in an effort to improve the lives of patients undergoing lung cancer surgery.

\section{Author contributions}

Conception and design: ESK, C-GY, YTK, CHK, IKP; analysis and interpretation of the data: ESK, C-HL, C-GY; drafting of the article: ESK, C-GY; critical revision of the article for important intellectual content: ESK, C-HL, C-GY, YWK, SKH; final approval of the article: ESK, YTK, CHK, IKP, WB, SMC, JL, YSP, C-HL, S-ML, J-JY, YWK, SKH, C-GY. All authors contributed toward data analysis, drafting and critically revising the paper and agree to be accountable for all aspects of the work.

\section{Disclosure}

The authors report no conflicts of interest in this work.

\section{References}

1. Wang J, Olak J, Ultmann RE, Ferguson MK. Assessment of pulmonary complications after lung resection. Ann Thorac Surg. 1999;67(5): 1444-1447.

2. Hazelrigg SR, Landreneau RJ, Boley TM, et al. The effect of musclesparing versus standard posterolateral thoracotomy on pulmonary function, muscle strength, and postoperative pain. J Thorac Cardiovasc Surg. 1991;101(3):394-400. [discussion 400-401].

3. Busch E, Verazin G, Antkowiak JG, Driscoll D, Takita H. Pulmonary complications in patients undergoing thoracotomy for lung carcinoma. Chest. 1994;105(3):760-766.

4. Bolliger CT, Jordan P, Soler M, et al. Exercise capacity as a predictor of postoperative complications in lung resection candidates. Am J Respir Crit Care Med. 1995;151(5):1472-1480.

5. Epstein SK, Faling LJ, Daly BD, Celli BR. Inability to perform bicycle ergometry predicts increased morbidity and mortality after lung resection. Chest. 1995;107(2):311-316.

6. Okita A, Yamashita M, Abe K, et al. Variance analysis of a clinical pathway of video-assisted single lobectomy for lung cancer. Surg Today. 2009;39(2):104-109.

7. Lawrence VA, Hilsenbeck SG, Mulrow CD, Dhanda R, Sapp J, Page CP. Incidence and hospital stay for cardiac and pulmonary complications after abdominal surgery. J Gen Intern Med. 1995;10(12):671-678.

8. Gupta H, Ramanan B, Gupta PK, et al. Impact of COPD on postoperative outcomes: results from a national database. Chest. 2013;143(6): 1599-1606.

9. Agostini P, Cieslik H, Rathinam S, et al. Postoperative pulmonary complications following thoracic surgery: are there any modifiable risk factors? Thorax. 2010;65(9):815-818.

10. Sekine Y, Suzuki H, Yamada Y, Koh E, Yoshino I. Severity of chronic obstructive pulmonary disease and its relationship to lung cancer prognosis after surgical resection. Thorac Cardiovasc Surg. 2013;61(2):124-130.

11. Lopez-Encuentra A, Astudillo J, Cerezal J, et al; Bronchogenic Carcinoma Cooperative Group of the Spanish Society of Pneumology and Thoracic Surgery (GCCB-S). Prognostic value of chronic obstructive pulmonary disease in 2994 cases of lung cancer. Eur J Cardiothorac Surg. 2005;27(1):8-13.

12. Lawrence VA, Dhanda R, Hilsenbeck SG, Page CP. Risk of pulmonary complications after elective abdominal surgery. Chest. 1996;110(3): 744-750.

13. Myrdal G, Gustafsson G, Lambe M, Horte LG, Stahle E. Outcome after lung cancer surgery. Factors predicting early mortality and major morbidity. Eur J Cardiothorac Surg. 2001;20(4):694-699.

14. Patel RL, Townsend ER, Fountain SW. Elective pneumonectomy: factors associated with morbidity and operative mortality. Ann Thorac Surg. 1992;54(1):84-88.

15. Bernard A, Deschamps C, Allen MS, et al. Pneumonectomy for malignant disease: factors affecting early morbidity and mortality. $J$ Thorac Cardiovasc Surg. 2001;121(6):1076-1082.

16. Wahi R, McMurtrey MJ, DeCaro LF, et al. Determinants of perioperative morbidity and mortality after pneumonectomy. Ann Thorac Surg. 1989;48(1):33-37.

17. Kearney DJ, Lee TH, Reilly JJ, DeCamp MM, Sugarbaker DJ. Assessment of operative risk in patients undergoing lung resection. Importance of predicted pulmonary function. Chest. 1994;105(3):753-759.

18. Pierce RJ, Copland JM, Sharpe K, Barter CE. Preoperative risk evaluation for lung cancer resection: predicted postoperative product as a predictor of surgical mortality. Am J Respir Crit Care Med. 1994;150(4):947-955.

19. Stephan F, Boucheseiche S, Hollande J, et al. Pulmonary complications following lung resection: a comprehensive analysis of incidence and possible risk factors. Chest. 2000;118(5):1263-1270.

20. Brunelli A, Al Refai M, Monteverde M, Borri A, Salati M, Fianchini A. Stair climbing test predicts cardiopulmonary complications after lung resection. Chest. 2002;121(4):1106-1110.

21. Licker MJ, Widikker I, Robert J, et al. Operative mortality and respiratory complications after lung resection for cancer: impact of chronic obstructive pulmonary disease and time trends. Ann Thorac Surg. 2006; 81(5):1830-1837. 
22. Kroenke K, Lawrence VA, Theroux JF, Tuley MR, Hilsenbeck S. Postoperative complications after thoracic and major abdominal surgery in patients with and without obstructive lung disease. Chest. 1993;104(5): 1445-1451.

23. Yano T, Miura N, Takenaka T, et al. Never-smoking nonsmall cell lung cancer as a separate entity: clinicopathologic features and survival. Cancer. 2008;113(5):1012-1018.

24. Subramanian J, Govindan R. Lung cancer in 'never-smokers': a unique entity. Oncology. 2010;24(1):29-35.

25. Standards for the diagnosis and care of patients with chronic obstructive pulmonary disease. American Thoracic Society. Am J Respir Crit Care Med. 1995;152(5 pt 2):S77-S121.

26. Vestbo J, Hurd SS, Agusti AG, et al. Global strategy for the diagnosis, management, and prevention of chronic obstructive pulmonary disease: GOLD executive summary. Am J Respir Crit Care Med. 2013;187(4): 347-365.

27. Sekine Y, Yamada Y, Chiyo M, et al. Association of chronic obstructive pulmonary disease and tumor recurrence in patients with stage IA lung cancer after complete resection. Ann Thorac Surg. 2007;84(3):946-950.

28. Smetana GW, Lawrence VA, Cornell JE; American College of Physicians. Preoperative pulmonary risk stratification for noncardiothoracic surgery: systematic review for the American College of Physicians. Ann Intern Med. 2006;144(8):581-595.

29. Wong DH, Weber EC, Schell MJ, Wong AB, Anderson CT, Barker SJ. Factors associated with postoperative pulmonary complications in patients with severe chronic obstructive pulmonary disease. Anesth Analg. 1995;80(2):276-284.

30. Arozullah AM, Daley J, Henderson WG, Khuri SF. Multifactorial risk index for predicting postoperative respiratory failure in men after major noncardiac surgery. The National Veterans Administration Surgical Quality Improvement Program. Ann Surg. 2000;232(2):242-253.

31. Gupta PK, Gupta H, Kaushik M, et al. Predictors of pulmonary complications after bariatric surgery. Surg Obes Relat Dis. 2012;8(5):574-581.

32. Ferguson MK, Little L, Rizzo L, et al. Diffusing capacity predicts morbidity and mortality after pulmonary resection. J Thorac Cardiovasc Surg. 1988;96(6):894-900.

33. Richter Larsen K, Svendsen UG, Milman N, Brenoe J, Petersen BN Exercise testing in the preoperative evaluation of patients with bronchogenic carcinoma. Eur Respir J. 1997;10(7):1559-1565.
34. Prescott E, Almdal T, Mikkelsen KL, Tofteng CL, Vestbo J, Lange P Prognostic value of weight change in chronic obstructive pulmonary disease: results from the Copenhagen City Heart Study. Eur Respir J. 2002;20(3):539-544.

35. Wilson DO, Rogers RM, Wright EC, Anthonisen NR. Body weight in chronic obstructive pulmonary disease. The National Institutes of Health Intermittent Positive-Pressure Breathing Trial. Am Rev Respir Dis. 1989; 139(6):1435-1438.

36. Gray-Donald K, Gibbons L, Shapiro SH, Macklem PT, Martin JG. Nutritional status and mortality in chronic obstructive pulmonary disease. Am J Respir Crit Care Med. 1996;153(3):961-966.

37. Landbo C, Prescott E, Lange P, Vestbo J, Almdal TP. Prognostic value of nutritional status in chronic obstructive pulmonary disease. Am J Respir Crit Care Med. 1999;160(6):1856-1861.

38. Arora NS, Rochester DF. Respiratory muscle strength and maximal voluntary ventilation in undernourished patients. Am Rev Respir Dis. 1982;126(1):5-8.

39. Arora NS, Rochester DF. Effect of body weight and muscularity on human diaphragm muscle mass, thickness, and area. J Appl Physiol. 1982;52(1):64-70.

40. Licker M, Spiliopoulos A, Frey JG, De Perrot M, Chevalley C, Tschopp JM. Management and outcome of patients undergoing thoracic surgery in a regional chest medical centre. Eur J Anaesthesiol. 2001;18(8):540-547.

41. Pei G, Zhou S, Han Y, Liu Z, Xu S. Risk factors for postoperative complications after lung resection for non-small cell lung cancer in elderly patients at a single institution in China. J Thorac Dis. 2014;6(9): 1230-1238.

42. Lee SW, Kim YS, Kim DS, Oh YM, Lee SD. The risk of obstructive lung disease by previous pulmonary tuberculosis in a country with intermediate burden of tuberculosis. J Korean Med Sci. 2011;26(2):268-273.

43. Snider GL, Doctor L, Demas TA, Shaw AR. Obstructive airway disease in patients with treated pulmonary tuberculosis. Am Rev Respir Dis. 1971;103(5):625-640.

44. Kirchhoff P, Dincler S, Buchmann P. A multivariate analysis of potential risk factors for intra- and postoperative complications in 1316 elective laparoscopic colorectal procedures. Ann Surg. 2008;248(2):259-265.

45. Kroenke K, Lawrence VA, Theroux JF, Tuley MR. Operative risk in patients with severe obstructive pulmonary disease. Arch Intern Med. 1992;152(5):967-971 


\section{Supplementary material}

Table SI Perioperative variables significantly associated with PPCs on univariate analysis

\begin{tabular}{llll}
\hline & $\begin{array}{l}\text { Without PPCs, } \\
\mathbf{N}=\mathbf{7 9}\end{array}$ & With PPCs, \\
$\mathbf{N}=\mathbf{3 4}$
\end{tabular}

Note: Significant differences between with and without PPCs were tested using chi-square, or Fisher's exact test. Data shown as ${ }^{a} \mathrm{mean}$ (SD), ${ }^{b}$ number (\%) patients, or 'median (range).

Abbreviations: BMI, body mass index; CAT, COPD assessment test; CXR, chest radiograph; $\mathrm{DL}_{\mathrm{co}}$, diffusing capacity of the lung for carbon monoxide; \% pred, percentage of the predicted value; PPCs, postoperative pulmonary complications; SGRQ, St George Respiratory Questionnaire; TB, tuberculosis.

\section{Publish your work in this journal}

The International Journal of COPD is an international, peer-reviewed journal of therapeutics and pharmacology focusing on concise rapid reporting of clinical studies and reviews in COPD. Special focus is given to the pathophysiological processes underlying the disease, intervention programs, patient focused education, and self management protocols.

\section{Dovepress}

This journal is indexed on PubMed Central, MedLine and CAS. The manuscript management system is completely online and includes a very quick and fair peer-review system, which is all easy to use. Visit $\mathrm{http}: / / \mathrm{www}$.dovepress.com/testimonials.php to read real quotes from published authors. 